\title{
TRANSFORMATIONS IN THE Ta-H AND Ta-D SYSTEMS
}

\author{
W. E. Wallage, Per Kofstad* and L. J. Hyvönen† \\ Department of Chemistry, University of Pittsburgh, Pittsburgh 13, Pennsylvania, \\ U.S.A.
}

\section{INTRODUGTION}

Elemental tantalum is known to dissolve large quantities of hydrogen or deuterium. In 1940 Kelley $^{1}$ published heat capacity data for tantalum and for tantalum containing 3,6 and 9 atomic per cent of hydrogen. Excess heat capacities in the temperature range $100^{\circ}$ to $300^{\circ} \mathrm{K}$ were observed for the binary system but not for the element. Diffraction studies by Waite, Wallace and Craig ${ }^{2}$ were carried out in an attempt to ascertain the origin of Kelley's thermal anomalies. This study showed that at the concentrations employed by Kelley the system consists of two phases: the primary solid solution of hydrogen in tantalum ( $\alpha$-phase) and a second phase ( $\beta$-phase) approximating the composition $\mathrm{Ta}_{2} \mathrm{H}$. Structure determinations showed the $\alpha$-phase to be body-centred cubic. The $\beta$-phase was found to be similar. It is, however, slightly distorted in the $c$-direction so that its axial ratio is 1.008 and its structure is hence body-centred tetragonal.

It now seems clear that the anomalies observed by Kelley resulted from the conversion of the two-phase system at low temperatures into a single phase $(\alpha)$ at high temperatures. This process is endothermal and gives rise to the observed excess heat capacity.

These results answer the question as to the origin of Kelley's anomalies but pose another, perhaps more interesting, question. What is the essential difference between the $\alpha$ and $\beta$ forms of $\mathrm{Ta}_{2} \mathrm{H}$ ? The $\alpha-\beta$ transformation, occurring at about $61^{\circ} \mathrm{C}$, has been under intensive investigation in our Laboratory for a number of months. It has been studied by the following techniques: X-ray diffraction, neutron diffraction, electrical resistance measurements, magnetic susceptibility determinations, and measurement of internal friction. In addition, very recently heat capacity measurements have been made in the vicinity of the transformation temperature.

\section{PHENOMENA WHIGH GOULD GIVE RISE TO THE $\alpha-\beta$ TRANSFORMATION}

Two possibilities have received consideration. One, the $61^{\circ} \mathrm{C}$ transformation could be a Néel point. If so the conversion of the antiferromagnetic $\beta-\mathrm{Ta}_{2} \mathrm{H}$ into paramagnetic $\alpha-\mathrm{Ta}_{2} \mathrm{H}$, could be detected, at least in principle, by magnetic susceptibility determinations. Measurement of the susceptibility of $\mathrm{Ta}_{2} \mathrm{H}$ by Cherry and Wallace ${ }^{3}$ showed a temperature-independent

\footnotetext{
* Permanent address: Central Institute for Industrial Research, Blindern, Oslo, Norway. $\dagger$ Permanent address: Department of Physics, University of Helsinki, Finland.
} 


\section{W. E. WALLACE, PER KOFSTAD AND L. J. HYVÖNEN}

susceptibility in the range of the $\alpha-\beta$ transformation and hence virtually excluded the possibility that the transformation is magnetic in origin.

The second possibility is that the transformation is due to the rearrangement of the hydrogens in the many-fold more abundant interstitial sites. That this is the case has been confirmed by neutron diffraction examination of $\mathrm{Ta}_{2} \mathrm{D}$. Patterns for $\mathrm{Ta}_{2} \mathrm{D}$ were obtained ${ }^{*}$ at $53^{\circ} \mathrm{C}$ and at room temperature, $78^{\circ} \mathrm{K}$ and $4.2^{\circ} \mathrm{K}$. The pattern at $53^{\circ} \mathrm{C}$ shows a unit cell identical with that indicated by X-ray diffraction measurements. It contains 2 atoms of $\mathrm{Ta}$ and 1 atom of $\mathrm{D}$. The patterns at the other temperatures indicated a unit cell with doubled parameters so that the cell has 8 times the volume of the X-ray unit cell and hence contains $16 \mathrm{Ta}$ and $8 \mathrm{D}$ atoms.

The enlargement of the unit cell immediately implies an ordering of the deuterium atoms at room temperature and below and suggests that the transition is an order-disorder transformation involving the interstitial hydrogens. This is also supported by measurement of the electrical resistance of a wire of $\mathrm{Ta}_{2} \mathrm{H}$. The resistance-temperature curve shows a sharp rise at the $\beta-\alpha$ transformation point.

\section{ARRANGEMENT OF DEUTERIUM ATOMS IN THE $\mathrm{Ta}_{2} D$ SUPERLATTIGE}

It is, of course, of great interest to determine the arrangement of the deuterium atoms in $\beta-\mathrm{Ta}_{2} \mathrm{D}$. The first attempts to accomplish this by analysis of the neutron diffraction patterns were consistently unsuccessful. It began to appear that a fully ordered structure had not been achieved for any of the temperatures studied. It seemed as if some of the deuteriums were statistically distributed over more than one site even at liquid helium temperatures. This introduced a serious complication into an already complex problem.

To ascertain the number of alternative sites available, one could make use of residual entropy measurements which had been under way for $\mathrm{Ta}_{2} \mathrm{H}$ in this Laboratory for a number of months. The residual entropy is evaluated by first obtaining the entropy change for the following reaction

$$
2 \mathrm{Ta}_{(\mathrm{s})}+\frac{1}{2} \mathrm{H}_{2(\mathrm{~g})} \longrightarrow \alpha-\mathrm{Ta}_{2} \mathrm{H}_{(\mathrm{s})}
$$

$\Delta S$ for this reaction may be evaluated by appropriate vapour pressure measurements in the range $300-400^{\circ} \mathrm{C}$. Using the known entropies of the elements the entropy of $\alpha-\mathrm{Ta}_{2} \mathrm{H}$ at $300^{\circ} \mathrm{C}$ is computed. From this the entropy of $\beta-\mathrm{Ta}_{2} \mathrm{H}$ at $0^{\circ} \mathrm{K}$ can be obtained if appropriate $C_{p}$ data for $\mathrm{Ta}_{2} \mathrm{H}$ are available. Details of the vapour pressure measurements and $C_{p}$ determinations are given in later sections.

Preliminary estimates of the residual entropy indicated a value of $R \ln 2$, suggesting that each hydrogen is statistically distributed over 2 sites. With this new information a satisfactory accounting for the neutron diffraction pattern was made with the deuterium atoms distributed over the tetrahedral interstices at $1 / 41 / 80,1 / 83 / 40,3 / 47 / 80,7 / 81 / 40,3 / 801 / 4,5 / 801 / 4$, $03 / 81 / 4,05 / 81 / 4,3 / 45 / 81 / 2,5 / 81 / 41 / 2,1 / 43 / 81 / 2,3 / 83 / 41 / 2,7 / 8$ $1 / 23 / 4,1 / 81 / 23 / 4,1 / 27 / 83 / 4,1 / 21 / 83 / 4$.

* Deep appreciation is expressed to Dr L. J. Corliss and his associates at the Brookhaven National Laboratory for providing these patterns. 


\section{HEAT CAPACITIES AND RESIDUAL ENTROPY OF Ta ${ }_{2} \mathrm{H}$}

$C_{p}$ values for $\mathrm{Ta}_{2} \mathrm{H}$ have been determined in this Laboratory for the range $1.4^{\circ}$ to $14^{\circ} \mathrm{K}$ (unpublished measurements of Galli, Sandmo and Craig ${ }^{4}$ ) and for $10^{\circ}$ to $545^{\circ} \mathrm{K}$ (unpublished measurements of Saba, Sandmo,

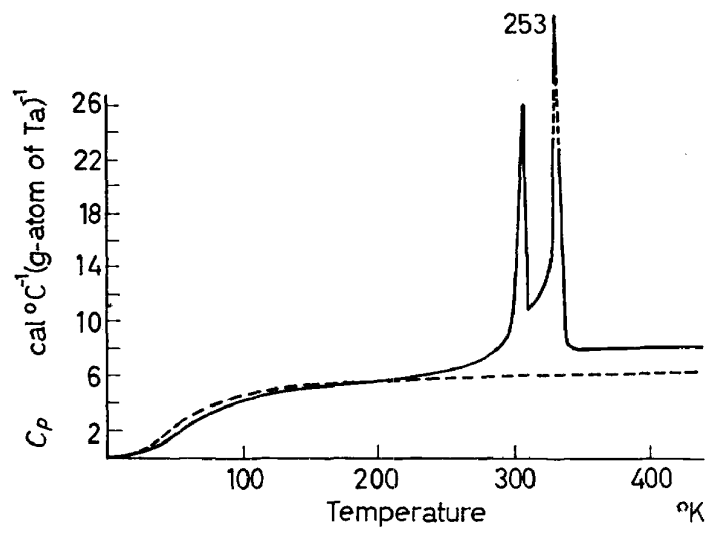

Figure 1. Temperature dependence of the heat capacity of $\mathrm{Ta}_{2} \mathrm{H}:---$, atomic heat capacity of $\mathrm{Ta}$

Wallace and Craig $\left.^{5}\right)$. These indicate the $\beta-\alpha$ transformation to be considerably more complex than had been originally assumed. The results (Figures 1 and 2) indicate that there are at least two and perhaps three forms of $\beta-\mathrm{Ta}_{2} \mathrm{H}$. The $\beta_{1}$ form exists below $37^{\circ} \mathrm{C}$ and $\beta_{2}$ from about $37^{\circ}$ to $60^{\circ} \mathrm{C}$. The double thermal anomaly at about $60^{\circ} \mathrm{C}$ suggests a third form, $\beta_{3}$.

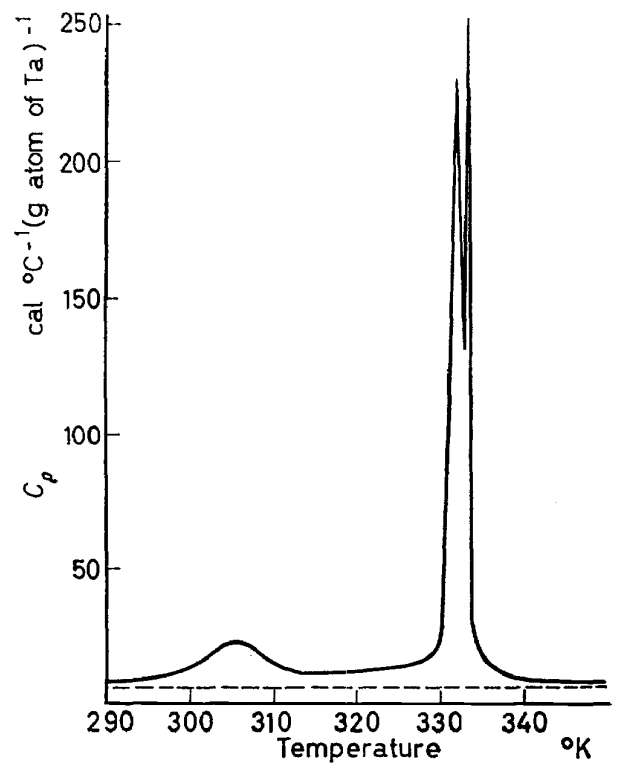

Figure 2. Heat capacities as functions of temperature: - - $\mathrm{Ta}$; $-\mathrm{Ta}_{2} \mathrm{H}$ 


\section{W. E. WALLACE, PER KOFSTAD AND L. J. HYVÖNEN}

The diffraction results indicate long-range order (with double site occupancy per atom) in $\beta_{1}-\mathrm{Ta}_{2} \mathrm{H}$. Long range order is destroyed at $37^{\circ} \mathrm{C}$, giving rise to the thermal anomaly observed at that temperature. Extensive short-range order (undoubtedly pairing) is retained. In this instance the short-range order is seemingly highly co-operative and is largely destroyed in $\beta-\mathrm{Ta}_{2} \mathrm{H}$ at $60^{\circ} \mathrm{C}$, giving rise to the pronounced thermal anomalies at that temperature.

More recently final values of the residual entropy of $\mathrm{Ta}_{2} \mathrm{H}$ have become available. In contrast with the result suggested by the preliminary estimate, the final values clearly indicate that $S_{0^{\circ} \mathrm{K}}$ for $\mathrm{Ta}_{2} \mathrm{H}$ is -0.13 e.u., with an estimated uncertainty of about $0 \cdot 10$ e.u. This indicates a unique arrangement of hydrogen atoms, a conclusion which contradicts that derived from the neutron diffraction pattern. This may signify that the arrangement of deuterium atoms cited in the earlier section is incorrect, but more likely implies short-range order (domain structure or the like) of the permitted occupancy in the $\beta_{1}$ structure. Support for this notion is provided by analysis of the $53^{\circ}$ pattern. This pattern (for $\beta_{2}-\mathrm{Ta}_{2} \mathrm{D}$ ) is comparatively simple and can be interpreted with great confidence to indicate an arrangement which places $1 / 8$ of a deuterium atom on the average in the tetrahedral interstices located at $1 / 21 / 40,1 / 23 / 40,1 / 41 / 20,3 / 41 / 20,01 / 41 / 2,03 / 41 / 2$, $1 / 401 / 2,3 / 401 / 2$. Superficially, this suggests a random distribution of the deuterium atoms over 8 sites. However, the observed configurational entropy of the $\beta_{2}-\mathrm{Ta}_{2} \mathrm{H}$ is about $1 / 9$ of the value expected if the deuterium atom were randomized over this number of sites. This indicates very extensive short-range order among the solute atoms.

\section{VAPOUR PRESSURE MEASUREMENTS}

The vapour pressure measurements show features which make them of interest quite apart from the issue of the residual entropy of $\mathrm{Ta}_{2} \mathrm{H}$. The results indicate that one is dealing with the single-phase primary solid solution up to the highest concentrations studied: $33 \frac{1}{3}$ atomic per cent of hydrogen. Between 2 and 20 atomic per cent of hydrogen $\sqrt{P}$ is linear with $\mathcal{N}_{\mathrm{H}}$ ( $P$ is the vapour pressure and $\mathcal{N}_{\mathrm{H}}$ is the atomic fraction of hydrogen) in accordance with ideal solution behaviour for a dissociating solute. This behaviour, known as Sievert's law, is no longer observed either in concentrated solutions or in dilute solutions. The latter deviations are expected and rather surprising. Upon dilution below $\mathcal{N}_{\mathbf{H}}=0.02$ the observed vapour pressures first increase above, and then diminish so as to fall below, the values expected from Sievert's law. The data indicate a nearly constant partial heat of vaporization of about $9 \mathrm{kcal} / \mathrm{g}$-atom of hydrogen for most of the composition range. Below $\mathcal{N}_{\mathrm{H}}=0.02$ this drops rapidly to a value of about $5 \mathrm{kcal} / \mathrm{g}$-atom at the lowest measured concentration. Hence the partial molal enthalpy of hydrogen is anomalously high in dilute solutions. Analysis of the data shows that this is also true of its partial molal entropy. These departures from expected behaviour produce the observed deviations from Sievert's law. The source of the extra enthalpy and entropy is not yet clear. One likely possibility is that the behaviour of hydrogen in dilute solutions is fundamentally different from that in concentrated solutions. In the latter the hydrogen is known to be "solid-like", that is it is localized 


\section{TRANSFORMATIONS IN THE Ta-H AND Ta-D SYSTEMS}

in an interstitial site for a time long compared with that required for one vibration. With dilution the site becomes smaller and, owing to Coulombic repulsion, the energy of the hydrogen becomes larger. Perhaps in sufficiently dilute solutions the energy of the hydrogen becomes sufficiently high for it to "sublime" out of the intersititial sites into the lattice, becoming " gas-like" in character. This would confer upon it extra entropy and extra enthalpy. Hence this type of transformation upon reducing the concentration could qualitatively account for the vapour pressure behaviour of the dilute alloys. Whether it actually occurs and is responsible for the observed deviations from Sievert's law must await the outcome of additional studies of this system.

\section{References}

${ }^{1}$ K. K. Kelley. 7. Chem. Phys., 8, 316 (1940)

2 T. R. Waite, W. E. Wallace and R. S. Craig. 7. Chem. Phys., 24, 634 (1956)

${ }^{3}$ L. V. Cherry and W. E. Wallace. Unpublished results

${ }^{4}$ C. Galli, H. Sandmo and R. S. Craig. Unpublished results

${ }^{5}$ W. G. Saba, H. Sandmo, W. E. Wallace and R. S. Craig. Unpublished results 